\title{
How should the IACUC balance an efficient approval process with minimizing risk?
}

\author{
Jerald Silverman, DVM
}

As if it wasn't hard enough to get a protocol approved by the Great Eastern University IACUC, it became even harder, or at least more frustrating, for Dr. Joyce Neiman when her protocol's "final" approval was delayed while waiting for an approval from the school's Department of Occupational Health and Safety (OHS). This was a standard practice for any study that used a controlled substance as a test material rather than for veterinary clinical use, and Neiman's lab would be studying opioid metabolism in various animal species.

The OHS approval for Neiman's study arrived at the IACUC office about a week after the IACUC's approval and it included detailed instructions on drug safety, secu- rity, record keeping and disposal. It also required that Neiman and her research staff sign a copy of the instructions to indicate their agreement with the OHS requirements. Neiman gathered the needed staff signatures and returned the signed instruction form to the IACUC office. However, the office staff told her that the protocol still required a "final approval" by the IACUC and the next full committee meeting would be in three weeks. Neiman thought that was ridiculous because the IACUC had already approved the protocol and she didn't see why it now had to approve the signed OHS instruction form. Nevertheless, rather than getting into an argument with the IACUC office staff, she volunteered to person- ally get the final approval signatures from the IACUC members and bring them to the office. However, the office told her that would be considered polling and federal regulations did not allow for a vote by polling. She then asked to have the final approval processed by the designated member review process, but she was informed that at Great Eastern, designated member review typically took at least two weeks, and in terms of time, it was probably safer for her to just have the protocol approved at the full committee meeting.

Is the Great Eastern IACUC unreasonably delaying the start of Neiman's research or is the IACUC office just playing by the rules?

\section{RESPONSE}

\section{Playing by the rules, but processes could be more PI friendly}

\author{
Carole R Baskin ${ }^{1}$, John Long ${ }^{2}$, Cheri L \\ West $^{2}$ \& Jana M Dodge ${ }^{2}$
}

This scenario brings up several questions: can/should an IACUC protocol be delayed until all ancillary institutional committee applications are reviewed and approved? Once they are approved, should the IACUC protocol go through another round of review by Designated Member Review or Full Committee, as the case may be? Can a PI get approval signatures from individual IACUC member, otherwise known as 'polling'?

According to the Public Health Service Policy ${ }^{1}$, organizations must base their animal care and use programs on the Guide for the Care and Use of Laboratory Animals ${ }^{2}$.
The Guide requires that an Occupational Health and Safety Program (OHSP) be part of the animal care and use program ${ }^{3}$ and it references the Occupational Health and Safety in the Care and Use of Research Animals ${ }^{4}$ as guidance on establishment and performance of an OHSP. Examples of oversight of OHSP Program include, but are not limited to, verification of enrollment, training of individuals on Animal Use Protocols ${ }^{5}$; compliance with ancillary institutional committees such as the Institutional Biosafety, Radiation Safety, Institutional Review Board and Chemical Safety $^{6}$. The IACUC is also required to review the OHSP during its semi-annual program evaluation $^{6}$, which considers "some of the most important personnel issues, [..] the occupational health and safety of animal care, use, and support personnel"7 and including the "use of hazardous materials and provision of a safe working environment" 2 . The IACUC must report deficiencies in the OHSP to OLAW/NIH ${ }^{7}$.
These expectations are not surprising as the Program has unique insights about the presence of biological, chemical, or radiation hazards in feed, animal secretions, and animal waste and about the extent of potential human exposure during animal experimentation and husbandry. Although the institution carries the ultimate responsibilities for establishing and administering a functional OHSP, the IACUC is responsible for day to day oversight for all parts of the Program, including the OHSP ${ }^{7}$. Therefore, the IACUC is the best position for approval of animal use activities involving hazards ${ }^{6}$. Indeed, the IACUC Handbook $^{7}$ states that the IACUC must have members with sufficient technical expertise to evaluate health risks associated with Animal Use Protocols, so the implication is that safety committees inform the IACUC review process, rather than review in parallel with the IACUC, although two-way communication is critical to ensure personnel safety. In fact, one 